\title{
COMP Regimen
}

National Cancer Institute

\section{Source}

National Cancer Institute. COMP Regimen. NCI Thesaurus. Code C9562.

A chemotherapy regimen consisting of cyclophosphamide, vincristine, methotrexate, and prednisone that may be used in the treatment of non-Hodgkin lymphoma (NHL). 